\title{
Scattering Month and Day of Baby Delivery in a Retrospective Survey Linked to 1484 Patients With Multiple Sclerosis
}

\author{
Zahra Tolou-Ghamari ${ }^{1, *}$ \\ ${ }^{1}$ Isfahan Neurosciences Research Centre, Faculty of Medicine, Isfahan University of Medical Sciences, Isfahan, IR Iran \\ ${ }^{*}$ Corresponding author: Zahra Tolou-Ghamari, Isfahan Neurosciences Research Centre, Faculty of Medicine, Isfahan University of Medical Sciences, Isfahan, IR Iran. \\ Tel: +98-3136291050, Fax: +98-3136680011, E-mail: toloeghamari@pharm.mui.ac.ir
}

Received: January 24, 2015; Revised: March 1, 2015; Accepted: March 12, 2015

\begin{abstract}
Background: Multiple Sclerosis (MS) is an inflammatory demyelinating disease leading to formation of brain lesions that could produce numerous devastating clinical problems. There are controversial reports related to the type of association of MS with the seasons of birth. Objectives: This study aimed to rank and describe the effect of different months and days of birth on MS.

Patients and Methods: The study was conducted in Isfahan University of Medical Sciences, Isfahan, Iran. A total of 1484 patients with MS were included: 1111 females and 373 males. Demographic and clinical data were recorded in a database and were analyzed using SPSS.

Results: The population of females with MS had surpassed that of males (75\% vs. 25\%). The mean age of patients was 34.7 years (range from 7 to 88 years) with $85 \%$ of population being younger than 50 years old. The season of birth was winter in $21 \%$ of patients. There was a decreased risk of MS in those born in February and March. The prevalence of MS increased from April and reached a peak in May and September. Day of birth was associated with the birthday on 19 th day of month in $44 \%$ of patients.

Conclusions: This investigation supports earlier reports of increased and diminished prevalence of MS in those born in the spring and winter months, respectively. Pharmacotherapy using vitamin D might have beneficial effect in Iranian population, especially in females during pregnancy and their newborns. Therefore, further clinical researches focused on prescription of vitamin D, genetic, daily photoperiod, and geo-epidemiologic differences of disease are recommended.
\end{abstract}

Keywords: Multiple Sclerosis; Seasons; Baby Delivery; Birth Timing

\section{Background}

In recent years, increased prevalence and incidence of multiple sclerosis (MS), mainly in females, has been reported (1). Demyelination of axons and loss of oligodendrocyte might be the result of heritable and environmental risk factors (2). The histopathologic change in MS-related trigeminal neuralgia after gamma-knife rhizotomy has been reported recently (3). In females, childhood and adolescence overweight could the exaggerate risk of MS (4). Vitamin D and its receptor (5) are expected to be another risk factor, as in vitro study showed that upregulation of vitamin D receptor and CYP24A might be induced in primary human astrocytes (6). Earlier publications reported that seasons of birth are a potential risk factor for the development of MS later in life. The maximum and minimum values were confirmed to be more related to spring and autumn, respectively (7). A statistically significant association between month of birth (MOB) and MS in 1035 patients in Kuwait showed that there were 13\% more MS births during December (8). An overall risk of migrant's MS birth showed slight tendency from September through February (9). A disease progression study in a large cohort of Italian patients showed no correlation between MS and MOB (10). Data from Latin America and
Portugal showed deficiency of seasonality model and doubted considering MOB as a specific risk factor for MS (11). Study of different latitudes of South America showed significant variation. Patients born to mothers who were pregnant at different Southern latitudes do not follow the seasonal pattern observed at high Northern latitudes (12). Regarding the MOB and risk of MS, vitamin D, as a promoter of some alleles, also promotes Th2 function and inhibit the proinflammatory cytokines, IL-1a, IL-2 $\beta$, and TNF $\alpha$ (13). A study in Sweden on 459 patients with MS reported that 25-hydroxy vitamin D at birth was not associated with risk of MS (14). Study of 6649 Norwegian patients with MS showed a higher frequency of April births (15). In 307 patients with longitudinally extensive spinal cord lesions, the pathogenesis of MS was correlated with MOB, which suggested some role for environmental factors (16). Study of Portugal group on 421 patients with MS could not support the seasonality of MOB as risk factor for MS (17). The correlation between MOB and the risk of MS seems to the most important in high-risk districts, particularly in the regions with low sunlight exposure $(18,19)$. Study of 6649 Norwegian patients with MS confirmed increase and decrease risk of MS in spring and winter, respectively (20). 


\section{Objectives}

While reported prevalence for Isfahan with a prevalence of 93.6 per 100000 people recommended a high risk area for MS, (21) this study aimed to assess the correlation between MOB and risk of MS within this population.

\section{Patients and Methods}

A total of 1484 patients with MS were studied at the Isfahan University of Medical Sciences, Isfahan, Iran. Patients' information such as first name, surname, age, date of birth, record No, and date of neurology visiting for methylprednisolone pulse therapy were recorded in a database. For each individual patient, day, month, and year of birth were converted from Persian calendar to Gregorian calendar. As a result, date of birth was recorded in the database in two forms: Persian and Gregorian. The converted Gregorian date of birth was used for further analysis. Iran is located the Northern hemisphere, more exactly, in Eastern Northern hemisphere. Northern hemisphere seasons include spring (1 March to 31 May), summer (1 June to 31 August), autumn (1 September to 30 November), and winter (1 December to 28 Friday). The statistical analysis of database was performed using (SPSS; Version 18)

\section{Results}

There were 1111 females (75\%) and 373 males. Distribution of patients' age was as follows: 10 to 20 years old, $4 \%$; 20 to 30 years old, $32 \%$; 30 to 40 years old, $33 \%$; 40 to 50 years old, $20 \%$; 50 to 70 years old, $10 \%$; and 70 to 88 years old, $1 \%$.

As shown in Figure 1, the patients' age ranged from seven to 88 years old with $65 \%$ of patients being 20 to 40 years old.

As shown in Figure 2, analysis of most frequent months of birth were consecutively September $(n=164)$, May $(\mathrm{n}=155)$, July $(\mathrm{n}=153)$, August $(\mathrm{n}=148)$, November $(\mathrm{n}$ $=136)$, October $(n=126)$, June $(n=120)$, December $(n=$ $115)$, April $(n=105)$, January $(n=101)$, February $(n=89)$, and March $(n=72)$. In comparison to other months, the number of patients with MS seems to be increased in April, May and September.

A further analysis of females $(\mathrm{n}=1111)$ with a mean age of 33.8 years (range, 8-87 years) showed that the most frequent MOBs were consecutively September $(n=123)$, August $(n=112)$, May $(n=109)$, November $(n=107)$, July $(n=105)$, October $(n=93)$, December $(n=92)$, June ( $n$ $=85)$, April $(n=83)$, January $(n=78)$, February $(n=68)$, and March $(n=56)$ (Figure 3$)$. In males $(n=373)$ with the mean age of 37.1 years (range, 7-88 years), the most frequent MOBs were consecutively July $(\mathrm{n}=48)$, May $(\mathrm{n}=$ $46)$, September $(n=41)$, August $(n=36)$, June $(n=35)$, October $(n=33)$, November $(n=29)$, December $(n=23)$, January $(n=23)$, April $(n=22)$, February $(n=21)$, and $\operatorname{March}(\mathrm{n}=16)$ (Figure 3$)$.

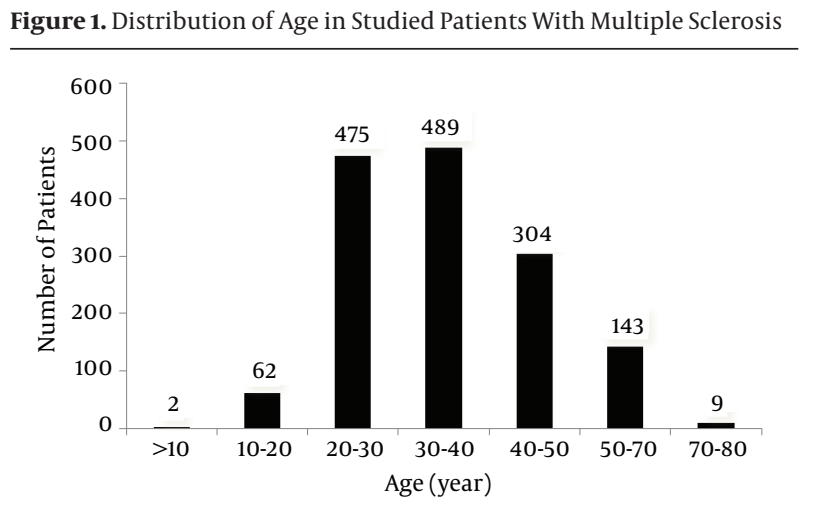

$(\mathrm{n}=1484)$.

Figure 2. Distribution of Month of Birth in Studied Patients With Multiple Sclerosis

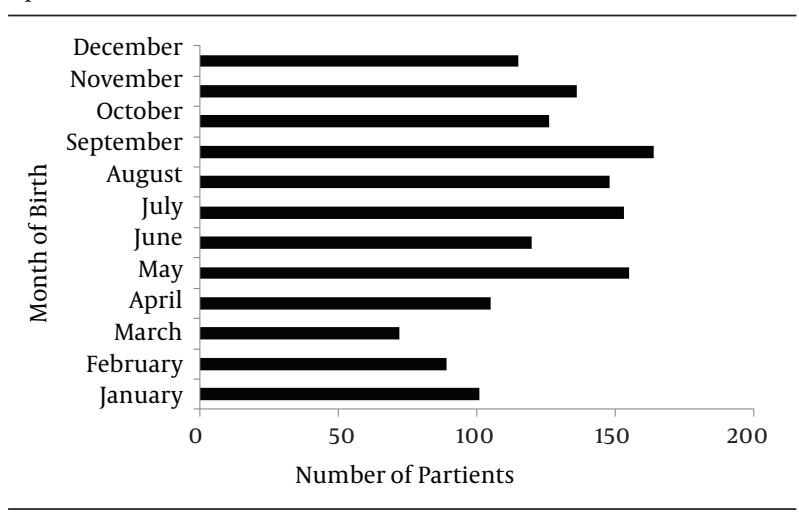

$(\mathrm{n}=1484)$.

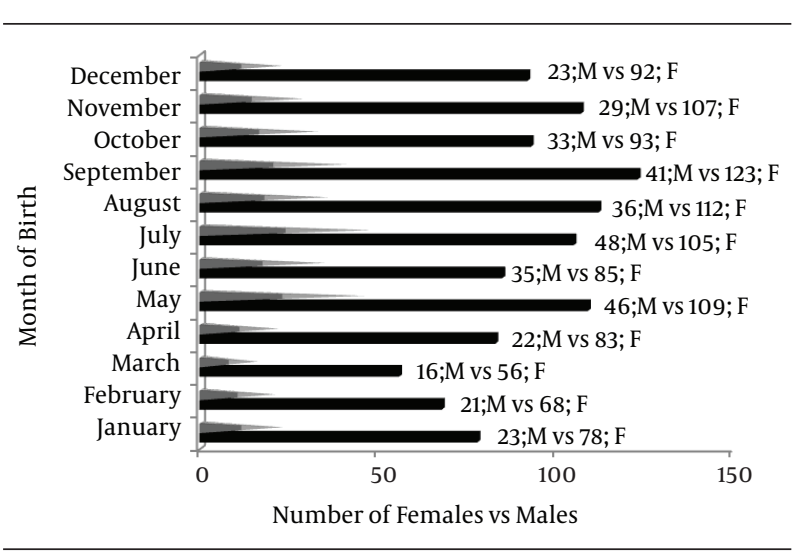

Figure 3. Distribution of Month of Birth in Females and Males With Multiple Sclerosis

Regarding the season of birth, adjusted date of birth according to the Northern hemisphere showed that the season of birth was associated to winter in the $21 \%$ of patients (Figure 4). A further analysis of the day of birth showed that it was in the second part of the month (after the 15th day) in the $69 \%$ of patients. Of this population, date of birth was the 19 th day of month in the $44 \%$ of patients (Figure 5 ). 


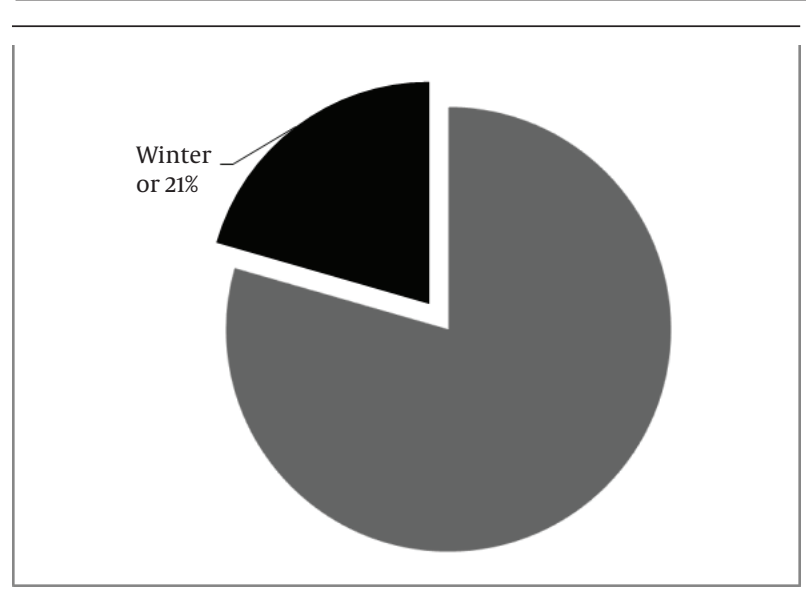

Figure 4. The Percentage of Multiple Sclerosis Population in Each Season

Figure 5. Distribution of Day of Birth in Patients With Multiple Sclerosis

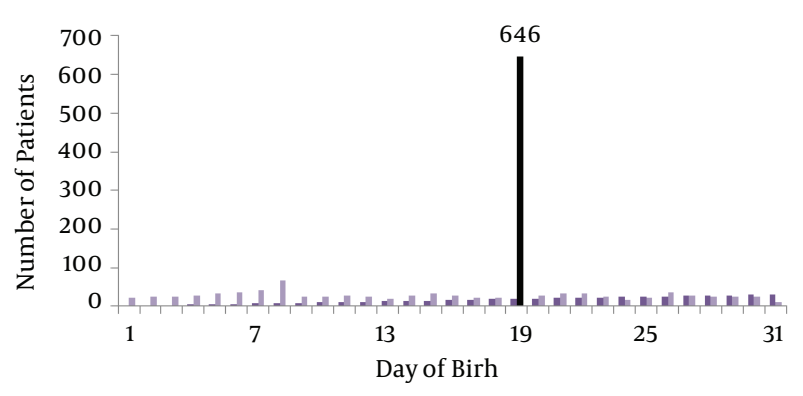

$(\mathrm{n}=1484)$.

\section{Discussion}

MS is a provocative disease distinguished by losing the myelin sheath of neurons in the central nervous system (22). Many factors such as environmental and genetic factors may play important role in developing MS (23). Susceptibility to develop MS and its association with MOB has been confirmed in some studies (10). The observed May/November birth ratio for places suggested that environmental factors are maternally mediated and influence development in the nervous or immune system, or both (24). Seasonal nutrient dissimilarity may also affect fetal growth at a cellular level (25). A MOB (May/November) effect shown in MS suggests that an unspecified environmental effect in early development can affect both MS susceptibility and phenotype (26). An excess of MS births in spring and a decrease in autumn (Northern hemisphere) also has been reported (18). Study performed by Koch reported that the season or MOB does not appear to influence disease progression (27). The possibility of maternal exposure to sunlight in increasing the development of MS later in life has been mentioned previously $(5,6)$.
In this study, the lowest population of patients with MS (21\%) was seen in winter. The highest prevalence was started from April, with a peak in May and September. In consistency with previous reports, only $25 \%$ of populations were males. Age in $65 \%$ of patients ranged from 20 to 40 years. This young society could provide a major financial burden for patient, family, and Iranian Ministry of Health.

To explain these results, many factors could influence the high prevalence of MS in young Iranian with MS. While hereditary feature might figure for a large susceptibility, geo-epidemiologic investigations propose the important role of environment regarding the disease commencement and intonation. A published report confirms that up to $20 \%$ of all MS cases are familial (28) and a further research connects MS to the HLA-DRB1 locus, with the HLA-DR15 haplotype (29). In another study, it has been confirmed that rs10767935 and rs5030244 in WT1 modify the IFN- $\beta-25(\mathrm{OH})$ D association in patients with MS (30). polymorphisms in genes involved in T-helper cell differentiation are associated with risk of developing MS. Initiation of neuroinflammation in animal models of MS has been shown to be dependent on T-helper cell-derived granulocyte-macrophage colony-stimulating factor (31). Lin X showed that 45 SNPs act as cis-effect regulators on 19 MS-associated genes. Among the 45 SNPs, 15 are most likely situated in transcription factor-binding sites, and five predicted SNPs (rs3095329 of TUBB, rs9469220/ rs2647046 of HLA-DQB1, rs11154801 of AHI1, and rs1062158 of NDFIP1) have corresponding target genes with significantly differential expressions in multiple cell groups, while rs7194 of HLA-DRA is predicted to be in the has-miR6507-3p binding site (32).

Regarding the environmental variables, recent publication classified many factors such as low obedience related to pharmacotherapy management, smoking, overweightness, low concentrations of vitamins A and D, use of high salt in food, and sedentary lifestyle (33).

In addition, not only the energy of biosphere and circadian rhythms are provided by solar radiation, but also genomes may be vigorously changed by it. The skin synthesis of vitamin D, as a strong immune modulator, after exposure to solar radiation could be changed by geographic and seasonal variation (34). The hours of daily exposure to sunlight or photoperiod could be also accountable for the association with latitude. The predictable affinity for latitudinal and chronological association might demonstrate advanced rates of birth in spring months and lower rates of birth in winter months (35). Additional research on risk factors related to genetic and environmental features seems to be a significant approach in the management of MS in Iranian population.

\section{Acknowledgements}

Thanks to Isfahan University of Medical Sciences. 


\section{References}

1. Ahlgren C, Oden A, Lycke J. High nationwide incidence of multiple sclerosis in Sweden. PLoS One. 2014;9(9):e108599.

2. Bradford CM, Ramos I, Cross AK, Haddock G, McQuaid S, Nicholas AP, et al. Localisation of citrullinated proteins in normal appearing white matter and lesions in the central nervous system in multiple sclerosis. J Neuroimmunol. 2014;273(1-2):85-95.

3. Phillips DB, Del Bigio MR, Kaufmann AM. Gamma Knife rhizotomy-induced histopathology in multiple sclerosis-related trigeminal neuralgia. J Neurosurg. 2014;121(6):1508-13.

4. Gianfrancesco MA, Acuna B, Shen L, Briggs FBS, Quach H, Bellesis $\mathrm{KH}$, et al. Obesity during childhood and adolescence increases susceptibility to multiple sclerosis after accounting for established genetic and environmental risk factors. Obes Res Clin Pract. 2014;8(5):e435-47.

5. Lv Z, Tang B, Sun Q, Yan X, Guo J. Association study between vitamin $\mathrm{d}$ receptor gene polymorphisms and patients with Parkinson disease in Chinese Han population. Int $J$ Neurosci. 2013;123(1):60-4.

6. Smolders J, Schuurman KG, van Strien ME, Melief J, Hendrickx D, Hol EM, et al. Expression of vitamin D receptor and metabolizing enzymes in multiple sclerosis-affected brain tissue. J Neuropathol Exp Neurol. 2013;72(2):91-105.

7. Nikseresht A, Sharifian M, Hamidian Jahromi A. Month of birth and the incidence of multiple sclerosis in southern iran. Iran J Med Sci. 2014;39(2 Suppl):232-3.

8. Akhtar S, Alroughani R, Al-Shammari A, Al-Abkal J, Ayad Y. Month of birth and risk of multiple sclerosis in Kuwait: a populationbased registry study. Mult Scler. 2015;21(2):147-54.

9. Akhtar S, Alroughani R, Al-Shammari A, Al-Abkal J, Ayad Y. Nonparametric analysis of seasonality in birth and multiple sclerosis risk in second generation of migrants in Kuwait. BMC Neurol. 2014;14:170.

10. Lucenti A, Galimberti S, Barizzone N, Naldi P, Comi G, Martinelli Boneschi F, et al. Multiple sclerosis progression is not associated with birth timing in Italy. J Neurol Sci. 2014;346(1-2):194-6.

11. Sa MJ. Month of birth is not a definite risk factor for multiple sclerosis. Arq Neuropsiquiatr. 2014;72(5):397.

12. Fragoso YD, Adoni T, Almeida SM, Alves-Leon SV, Arruda WO Barbagelata-Aguero F, et al. Multiple sclerosis in South America: month of birth in different latitudes does not seem to interfere with the prevalence or progression of the disease. Arq Neuropsiquiatr. 2013;71(9A):573-9.

13. Pimentel ML. Multiple sclerosis in the Southern and Northern hemispheres: the month of birth at different latitudes has the same influence on the prevalence and progression of the disease in the Northern and Southern hemispheres? Arq Neuropsiquiatr. 2013;71(9A):569-70.

14. Ueda P, Rafatnia F, Baarnhielm M, Frobom R, Korzunowicz G, Lonnerbro R, et al. Neonatal vitamin D status and risk of multiple sclerosis. Ann Neurol. 2014;76(3):338-46.

15. Torkildsen O, Aarseth J, Benjaminsen E, Celius E, Holmoy T, Kampman MT, et al. Month of birth and risk of multiple sclerosis: confounding and adjustments. Ann Clin Transl Neurol. 2014;1(2):141-4

16. Araki Y, Kinoshita M, Motoyama R, Matsushita T, Nakagawa M Kira J, et al. Month of birth in multiple sclerosis with and without longitudinally extensive spinal cord lesions: a study of a Japanese national survey. J Neurol Sci. 2013;330(1-2):67-70.

17. Barros P, de Sa JM, Sa MJ. Month of birth and risk of multiple sclerosis in a Portuguese population. Clin Neurol Neurosurg. 2013;115(9):1762-5.

18. Torkildsen O, Grytten N, Aarseth J, Myhr KM, Kampman MT Month of birth as a risk factor for multiple sclerosis: an update. Acta Neurol Scand Suppl. 2012(195):58-62.

19. Disanto G, Chaplin G, Morahan JM, Giovannoni G, Hypponen E, Ebers GC, et al. Month of birth, vitamin D and risk of immunemediated disease: a case control study. BMC Med. 2012;10:69.

20. Grytten N, Torkildsen O, Aarseth JH, Benjaminsen E, Celius EG, Dahl OP, et al. Month of birth as a latitude-dependent risk factor for multiple sclerosis in Norway. Mult Scler. 2013;19(8):1028-34.

21. Etemadifar M, Sajjadi S, Nasr Z, Firoozeei TS, Abtahi SH, Akbari M, et al. Epidemiology of multiple sclerosis in Iran: a systematic review. Eur Neurol. 2013;70(5-6):356-63.

22. Ozcan ME, Ince B, Bingol A, Erturk S, Altinoz MA, Karadeli HH, et al. Association between smoking and cognitive impairment in multiple sclerosis. Neuropsychiatr Dis Treat. 2014;10:1715-9.

23. Farez MF, Balbuena Aguirre ME, Varela F, Kohler AA, Nagel V, Correale J. Low familial risks for multiple sclerosis in Buenos Aires, Argentina. J Neurol Sci. 2014;346(1-2):268-70.

24. Tremlett HL, Devonshire VA. Does the season or month of birth influence disease progression in multiple sclerosis? Neuroepidemiol. 2006;26(4):195-8.

25. Watson PE, McDonald BW. Seasonal variation of nutrient in take in pregnancy: effects on infant measures and possible influence on diseases related to season of birth. Eur J Clin Nutr. 2007;61(11):1271-80.

26. Sadovnick AD, Duquette P, Herrera B, Yee IM, Ebers GC. A timing of-birth effect on multiple sclerosis clinical phenotype. Neurology. 2007;69(1):60-2.

27. Koch M, De Keyser J, Tremlett H. Timing of birth and disease progression in multiple sclerosis. Mult Scler. 2008;14(6):793-8.

28. Binzer S, Binzer M, Kyvik KO, Imrell K, Hillert J, Stenager E. [Every fifth case of multiple sclerosis is familial.]. Ugeskr Laeger. 2014;176(3A).

29. Kaushansky N, Ben-Nun A. DQB1*06:02-Associated Pathogenic Anti-Myelin Autoimmunity in Multiple Sclerosis-Like Disease: Potential Function of DQB1*06:02 as a Disease-Predisposing Allele. Frontiers Oncol. 2014;4:280.

30. Sundal C, Baker M, Karrenbauer V, Gustavsen M, Bedri S, Glaser A, et al. Hereditary diffuse leukoencephalopathy with spheroids with phenotype of primary progressive multiple sclerosis. Eur J Neurol. 2015;22(2):328-33.

31. Hartmann FJ, Khademi M, Aram J, Ammann S, Kockum I, Constantinescu C, et al. Multiple sclerosis-associated IL2RA polymorphism controls GM-CSF production in human TH cells. Nat Commun. 2014;5:5056.

32. Lin X, Deng FY, Mo XB, Wu LF, Lei SF. Functional relevance for multiple sclerosis-associated genetic variants. Immunogenetics. 2015;67(1):7-14

33. Fragoso YD. Modifiable environmental factors in multiple sclerosis. Arq Neuropsiquiatr. 2014;72(11):889-94

34. McDowell TY, Amr S, Langenberg P, Royal W, Bever C, Culpepper WJ, et al. Time of birth, residential solar radiation and age at onset of multiple sclerosis. Neuroepidemiology. 2010;34(4):238-44.

35. Fiddes B, Wason J, Sawcer S. Confounding in association studies: month of birth and multiple sclerosis. I Neurol. 2014;261(10):1851-6. 